\title{
Risk of bias in observational studies using routinely collected data of comparative effectiveness research: a meta-research study
}

Van Thu Nguyen ${ }^{1,2^{*}}$ (D), Mishelle Engleton ${ }^{1}$, Mauricia Davison ${ }^{1,3}$, Philippe Ravaud ${ }^{1,3,4}$, Raphael Porcher ${ }^{1,3,4}$ and Isabelle Boutron ${ }^{1,3,4}$

\begin{abstract}
Background: To assess the completeness of reporting, research transparency practices, and risk of selection and immortal bias in observational studies using routinely collected data for comparative effectiveness research.

Method: We performed a meta-research study by searching PubMed for comparative effectiveness observational studies evaluating therapeutic interventions using routinely collected data published in high impact factor journals from $01 / 06 / 2018$ to 30/06/2020. We assessed the reporting of the study design (i.e., eligibility, treatment assignment, and the start of follow-up). The risk of selection bias and immortal time bias was determined by assessing if the time of eligibility, the treatment assignment, and the start of follow-up were synchronized to mimic the randomization following the target trial emulation framework.

Result: Seventy-seven articles were identified. Most studies evaluated pharmacological treatments (69\%) with a median sample size of 24,000 individuals. In total, $20 \%$ of articles inadequately reported essential information of the study design. One-third of the articles $(n=25,33 \%)$ raised some concerns because of unclear reporting $(n=6,8 \%)$ or were at high risk of selection bias and/or immortal time bias $(n=19,25 \%)$. Only five articles (25\%) described a solution to mitigate these biases. Six articles (31\%) discussed these biases in the limitations section.

Conclusion: Reporting of essential information of study design in observational studies remained suboptimal. Selection bias and immortal time bias were common methodological issues that researchers and physicians should be aware of when interpreting the results of observational studies using routinely collected data.
\end{abstract}

Keywords: Observational studies, Routinely collected data, Emulated trial, Meta-research, Risk of bias

\footnotetext{
* Correspondence: nguyenthuvandkh@gmail.com

${ }^{1}$ Centre of Research Epidemiology and Statistics (CRESS), Inserm, Université de Paris, F-75004 Paris, France

${ }^{2}$ Meta-Research Innovation Centre at Stanford (METRICS), Stanford University,

1265 Welch Rd, Stanford, CA 94305, USA

Full list of author information is available at the end of the article
}

(c) The Author(s). 2021 Open Access This article is licensed under a Creative Commons Attribution 4.0 International License, which permits use, sharing, adaptation, distribution and reproduction in any medium or format, as long as you give appropriate credit to the original author(s) and the source, provide a link to the Creative Commons licence, and indicate if changes were made. The images or other third party material in this article are included in the article's Creative Commons licence, unless indicated otherwise in a credit line to the material. If material is not included in the article's Creative Commons licence and your intended use is not permitted by statutory regulation or exceeds the permitted use, you will need to obtain permission directly from the copyright holder. To view a copy of this licence, visit http://creativecommons.org/licenses/by/4.0/. The Creative Commons Public Domain Dedication waiver (http://creativecommons.org/publicdomain/zero/1.0/) applies to the data made available in this article, unless otherwise stated in a credit line to the data. 


\section{Background}

Though randomized control trials (RCTs) are considered to provide the best evidence in comparative effectiveness research (CER), they also have some limitations $[1,2]$. They can often be resource-intensive and timeconsuming. As such, RCTs may not be able to detect effects on long-term outcomes or rare events [3-5]. Observational studies using routinely collected data have been used to complement RCTs [5-8]. Routinely collected health data (RCD) are generated from the daily operations of healthcare systems, recorded without a priori research question [6]. A broad range of sources (e.g., disease registries, health administrative data, quality/safety surveillance databases, electronic health records, and pharmacy data) hosts such routinely collected data and contains both drug exposure and clinical outcomes to be used to provide evidence on treatment effectiveness.

However, observational studies are limited by their susceptibility to bias [5, 9-11]. Hernán et al. published a framework for using observational data to emulate a target trial, a hypothetical pragmatic trial $[4,12]$. The framework suggested researcher explicitly specifying key components of this hypothetical trial such as eligibility criteria, treatment assignment, and the start of followup. The time when patients fulfill the eligibility criteria is assigned to one of the treatment strategies (i.e., fulfill the criteria to be classified as exposure or control), and starting the follow-up should be aligned to mimic the randomization process in an RCT $[3,4,12]$. By avoiding methodological pitfalls, this approach reduces the risk of bias of the effect estimate and hence produces more reliable results [13]. Cochrane has adopted this framework in the assessment of the risk of bias for non-randomized intervention studies [14].

This study aimed to assess the completeness of reporting essential information of study design and risk of bias due to failure to mimic the randomization in observational studies using routinely collected data for comparative effectiveness research. We did not aim to assess the extent that the bias could influence the conclusion of the included studies. After systematically reviewing the reporting and conducting of observational studies, we propose a checklist to help readers and reviewers to identify common methodological pitfalls of observational studies.

\section{Methods}

\section{Study design}

We conducted a meta-research study and reviewed the comparative effectiveness observational studies evaluating the therapeutic interventions with the use of routinely collected data published in high impact factor journals. We followed the Preferred Reporting Items for
Systematic Reviews and Meta-Analyses (PRISMA) guidelines [15].

\section{Search strategy}

We identified a convenience sample of the 7 highest impact factor journals of the InCites Journal Citation Reports categories medicine, general, and internal (New England Journal of Medicine, Lancet, JAMA, BMJ, Annals of Internal Medicine, BMC Medicine, and PLoS Medicine) and 3 highest impact factor journals in endocrinology and metabolism (Lancet Diabetes E Endocrinology, Diabetes Care, and Diabetes) and cardiac and cardiovascular systems (European Heart Journal, Journal of American College of Cardiology, and Circulation) that cover research on high prevalent diseases.

As all these ten journals were indexed on PubMed, we conducted a search on PubMed to identify the observational studies evaluating a comparative effectiveness question. To reflect contemporary reporting practices and methodological conduct, the search was narrowed to studies published between 01/06/2018 and 30/06/ 2020. The full search strategy is presented in Additional file 1: Table S1.

\section{Eligibility criteria}

We included cohort studies which evaluated a therapeutic intervention by using RCD [6]. Studies were eligible for inclusion if they (1) evaluated a therapeutic intervention, defined as a treatment-related to healing a disease, i.e., pharmaceuticals, surgery; (2) used RCD as the data source; and (3) answered a comparative effectiveness question, i.e., research aiming to identify which interventions work best for improving health. Studies that did not answer CER questions, studies without an abstract, and retracted papers were excluded. The inclusion and exclusion criteria for study selection are provided in Additional file 1: Table S2.

\section{Study screening and selection}

One reviewer (ME) screened all the titles and abstracts of the studies retrieved. A second reviewer (VNT) screened a sample of 775 (57\%) of 1357 articles excluded by ME. There was good agreement between the two reviewers with only 1 conflict. Then, each of the full texts was assessed by two of three reviewers (ME, VNT, MD) to ensure the eligibility of the study for data extraction. All conflicts were resolved through discussion, and a third reviewer was available to adjudicate. Literature search results were imported into Mendeley (https:// www.mendeley.com) to store, organize, and manage all references. The screening process was aided by the use of the Rayyan software [16]. 


\section{Data extraction}

Data from each article were extracted independently by two of the three reviewers (ME, VTN, and MD) using a standardized form created based on the framework for emulating a target trial proposed by Hernán et al. and
RECORD-PE reporting guideline for observational studies using routinely collected data for pharmacoepidemiology [4, 12, 14, 17]. The form was initially piloted and refined throughout the process (Additional file 1: Table S3 - data extraction form and Additional file 1:

Table 1 Situations when time points of eligibility, treatment assignment, and the start of follow-up are not aligned

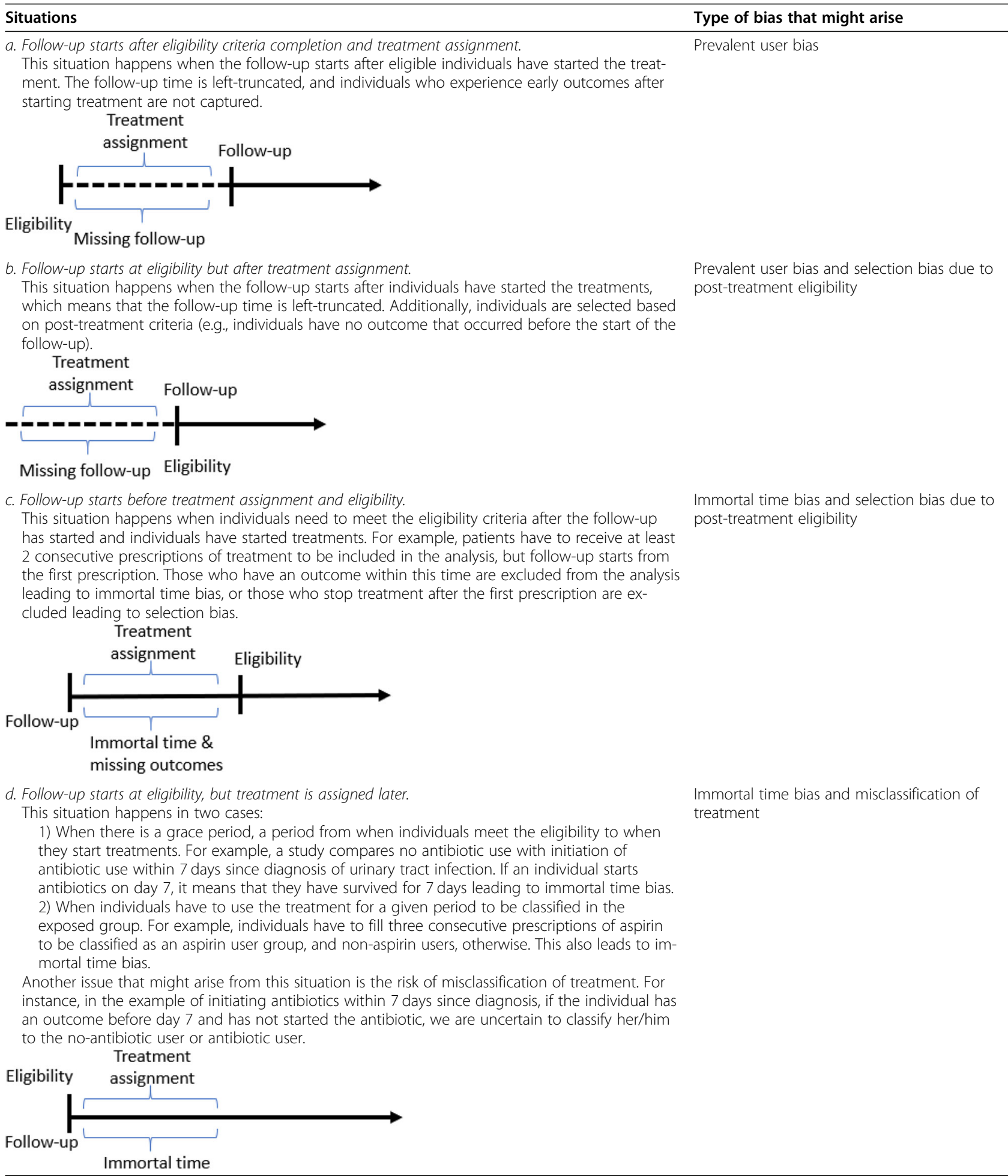


Table S4 - explanation of data items). Any disagreement was discussed with senior researchers (RP, IB) to reach a consensus. The following data were extracted from the selected papers:

1. Study characteristics: title, year of publication, author, location of the corresponding author, name of the journal, study design (longitudinal study), treatment type, comparator, funding source (i.e., public, private funding), and data source

2. Research transparency practices: use of reporting guidelines, access to codes and algorithms to classify exposures and outcomes, and data sharing policy

3. Reporting of essential items:

(a) Diagram to illustrate the study design (i.e., describing the time of eligibility, treatment assignment, and follow-up).

(b) Eligibility criteria, and particularly whether individuals with contraindication to one of the evaluated treatments, were explicitly excluded as in an RCT.

(c) Methods used to adjust for confounding (i.e., regression, propensity score, inverse probability weighting).

(d) Causal contrast of interest (i.e., intention-totreat effect, per-protocol effect).

(e) Time points of eligibility (i.e., when individuals were evaluated regarding their eligibility), treatment assignment (i.e., when individuals were classified to one of the treatment groups), and the start of follow-up (i.e., when individuals started outcome assessment).

4. After determining the time points of eligibility, treatment assignment, and the start of follow-up, we assessed if these time points were aligned to avoid bias. We identified the type of bias that might arise when they were not aligned (Table 1) and whether the authors described a solution to address bias.

\section{Data synthesis}

Categorical data were summarized using frequencies and percentages. Interrater reliability was tested using Cohen's kappa [18]. Descriptive analysis was completed in $\mathrm{R}$ (version 4.0.2).

\section{Data sharing}

Data of this study will be available on Zenodo after the publication of the article.

\section{Patient involvement}

Patients and public members were not involved in this study.

\section{Results}

\section{Study characteristics}

Among the 1465 articles retrieved from the search, 77 articles were selected for data extraction after screening for the title, abstract, and full text (Fig. 1).

Most of the studies were from North America and Europe and with a median sample size of 24,000 individuals. Ten articles (13\%) did not report the study design. Fifty-three studies (69\%) evaluated the pharmacological treatment. Forty-nine studies (63\%) compared against active comparators. The sources of data were registry $(n$ $=34 / 77,44 \%)$, electronic health record $(n=17 / 77,22 \%)$, administration data $(n=14 / 77,18 \%)$, and health insurance claims $(n=20,26 \%)$. Fifty-six percent of studies (43/77) received funding from not-for-profit organizations, and $13 \%(10 / 77)$ did not report the type of funding.

\section{Research transparency practices}

Only seven articles $(9 \%)$ mentioned the use of a reporting guideline. Fifty-three articles $(69 \%)$ provided codes (e.g., ICD-10 codes) used to classify both exposures and outcomes. Ten articles (13\%) indicated that data were available upon request (Table 2).

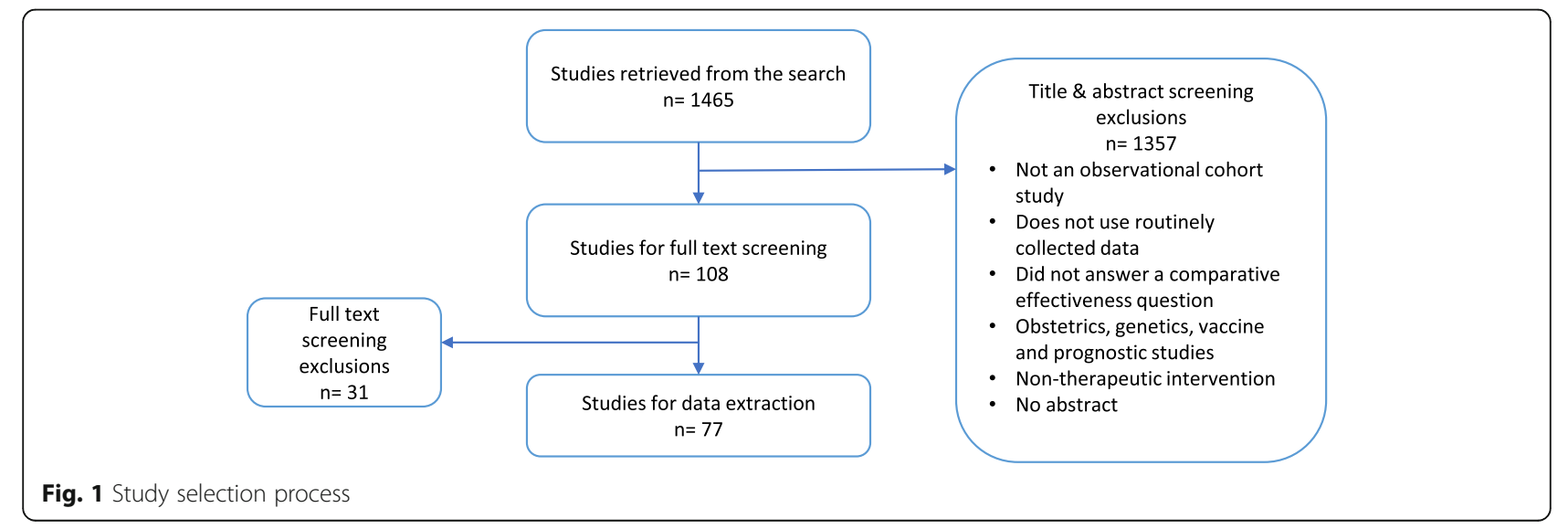


Table 2 Characteristics of included articles

\begin{tabular}{|c|c|}
\hline & $N=77(\%)$ \\
\hline \multicolumn{2}{|l|}{ Name of journal } \\
\hline$-N E J M$ & $3(4)$ \\
\hline - The Lancet & $2(3)$ \\
\hline - JAMA & $13(17)$ \\
\hline - Annals of Internal Medicine & $9(11)$ \\
\hline$-B M J$ & $14(18)$ \\
\hline - PLoS Medicine & $8(11)$ \\
\hline - Circulation & $7(9)$ \\
\hline - European Heart Journal & $4(5)$ \\
\hline - Journal of the American College of Cardiology & $15(19)$ \\
\hline \multicolumn{2}{|l|}{ Location of corresponding authors } \\
\hline - North America & $40(52)$ \\
\hline - Europe & $25(32)$ \\
\hline - Asia & $10(13)$ \\
\hline - North American and Europe & $1(1)$ \\
\hline - International & $1(1)$ \\
\hline \multicolumn{2}{|l|}{ Study design } \\
\hline - Cohort study & $67(87)$ \\
\hline - Not clearly reported & $10(13)$ \\
\hline \multicolumn{2}{|l|}{ Treatment evaluated } \\
\hline - Pharmacological treatment & $53(69)$ \\
\hline - Non-pharmacological treatment & $23(30)$ \\
\hline - Both & $1(1)$ \\
\hline \multicolumn{2}{|l|}{ Comparator } \\
\hline - Active comparator & $49(63)$ \\
\hline - Usual care & $17(22)$ \\
\hline - No treatment & $11(14)$ \\
\hline Median sample size [min-max] & $\begin{array}{l}24,000 \text { [9100- } \\
80,000]\end{array}$ \\
\hline \multicolumn{2}{|l|}{ Data source ${ }^{a}$} \\
\hline - Registry & $34(44)$ \\
\hline - Electronic health record & $17(22)$ \\
\hline - Health administration data & $14(18)$ \\
\hline - Health insurance claims data & $20(26)$ \\
\hline - Others & $11(14)$ \\
\hline \multicolumn{2}{|l|}{ Funding source } \\
\hline - Not for profit & $43(56)$ \\
\hline - For profit & $7(9)$ \\
\hline - Both & $12(16)$ \\
\hline - No funding & $5(6)$ \\
\hline - Unclear & $10(13)$ \\
\hline \multicolumn{2}{|l|}{ Research transparency practices } \\
\hline - Using a reporting guideline & 7 (9) \\
\hline
\end{tabular}

Table 2 Characteristics of included articles (Continued)

\begin{tabular}{ll}
\hline & $\mathbf{N}=\mathbf{7 7}(\mathbf{\%})$ \\
\hline $\begin{array}{l}\text { - Code and algorithm used to classify exposures } \\
\text { provided in supplementary documents }\end{array}$ & $57(74)$ \\
- Code and algorithm used to classify outcomes & $60(78)$ \\
provided in supplementary documents & \\
- A statement to provide data upon request & $10(13)$
\end{tabular}

${ }^{\mathrm{a} O n e}$ study might have more than one type of data sources

Reporting essential information of the target trial

Only $18 \%$ ( $n=14 / 77$ ) reported a diagram to illustrate the study design and reported the three essential time points (i.e., eligibility, treatment initiation, start of follow-up). Eighteen percent $(n=14 / 77)$ did not report completely essential time points, i.e., the start of followup, when individuals completed the eligibility criteria and when patients started the treatments of interest. Regarding the inclusion criteria, only $12 \%(n=9 / 77)$ reported the exclusion of patients with contraindication to one of the evaluated interventions. Only one article explained the reason for not excluding patients with such a contraindication, due to the inability to identify these patients from the dataset. Sixty-five percent of articles $(n=$ $50 / 77$ ) did not specify the type of causal contrast estimated (Table 3).

\section{Risk of bias due to failure of specifying a target trial}

Overall, 33\% ( $n=25 / 77)$ raised concerns about the risk of bias. Of these, in one-fourth $(n=6 / 25)$, as the start of follow-up was not clearly reported, we could not determine if eligibility, treatment assignment, and the start of follow-up were synchronized (Fig. 1). In 76\% $(n=19 /$ $25)$, the time when patients completed the eligibility criteria, initiated the treatments, and the start of follow-up was not aligned (Fig. 1). Among these 19 articles, in four articles $(n=4 / 19,21 \%)$, the follow-up started when patients met eligibility but after patients initiated treatment (Table 1 (b)), which led to prevalent user bias and selection bias due to post-treatment eligibility [19-22]. The authors did not describe any solutions to address these biases in these four articles.

In seven articles $(n=7 / 19,37 \%)$, the follow-up started when patients initiated treatment but before patients met the eligibility criteria leading to immortal time bias and selection bias due to post-treatment eligibility (Table 1 (c)) [23-29]. Among these, one article reported handling treatment exposure as a time-dependent variable to account for immortal time bias; however, this strategy was inadequate to account for selection bias due to post-treatment eligibility [25]. One article performed a sensitivity analysis to include participants who were excluded based on the post-treatment eligibility criteria and yielded similar results to the main analysis [27]. 
Table 3 Reporting of essential information

\begin{tabular}{ll}
\hline Reporting of essential information & $\mathbf{N}=\mathbf{7 7}$ (\%) \\
\hline Study characteristics & $2(3)$ \\
- Specification of the target trial & $14(18)$ \\
- Using a diagram to illustrate study design & \\
Eligibility criteria & $76(99)$ \\
- Inclusion criteria for the study & $9(12)$ \\
- Post-baseline events in inclusion criteria & \\
(e.g., use of treatment, no follow-up data) & $9(12)$ \\
- Exclusion of individuals with contraindications & \\
for interventions evaluated & \\
Adjustment for confounders & $60(70)$ \\
- Propensity score & $10(12)$ \\
- Inverse probability weighting & $15(17)$ \\
- Multivariable regression & $2(2)$ \\
- Instrumental variable & \\
Outcome & $77(100)$ \\
- Primary outcome reported & \\
Causal contrast of interests & $72(94)$ \\
- Intention-to-treat effect & $68(88)$ \\
- Per-protocol effect & $63(81)$ \\
- Both & $11(14)$ \\
- Noy specified & $6(8)$ \\
- Time point of the start of follow-up & $10(13)$ \\
- Time point of eligibility criteria & $50(65)$ \\
\hline
\end{tabular}

In seven articles $(n=7 / 19,37 \%)$, follow-up started when patients met the eligibility criteria, but patients were assigned to one of the treatment groups after the start of the follow-up, a situation both at risk of immortal time bias and misclassification of treatment (Table 1 (d)) [30-37]. Of these, four articles did not mention any solutions leading to high risk of selection bias [31, 32, 35, 37]; three articles treated treatment exposure as a time-dependent variable [30, 33, 36] which was inadequate to address the risk of misclassification, and one article randomly assigned individuals who had outcomes before treatment initiation to one of the two treatment groups [34] to mitigate the risk of bias. In one article $(n=1 / 19,5 \%)$, individuals could start the treatment both before and after eligibility and the start of follow-up (Table 1 (b and d)); thus, the study was at risk of prevalent user bias and immortal time bias [38]. No solution was described in this article. Among these 19 articles that we identified biases, six articles (32\%) discussed these biases in the limitations section (Fig. 2).

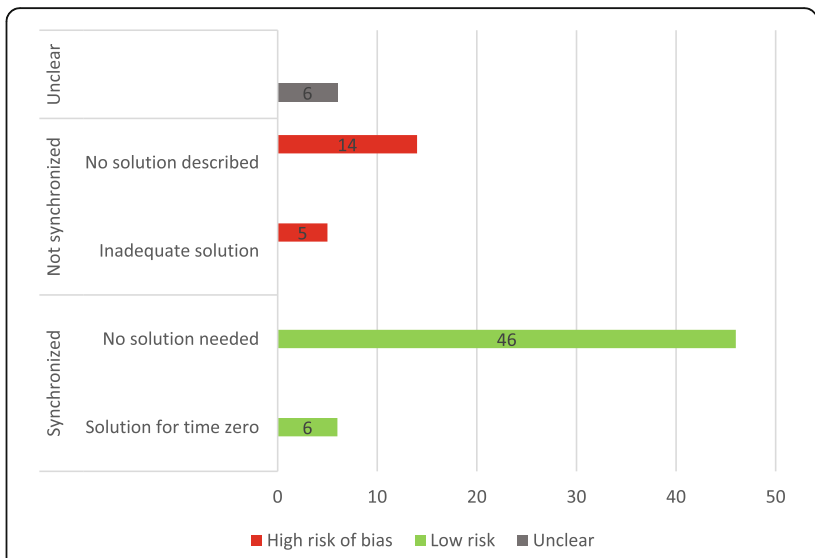

Fig. 2 The number of studies at risk of bias due to lack of synchronization. Nineteen (25\%) studies had a high risk of bias due to the lack of synchronization. Of these, 14 proposed no solution, and 5 used inadequate methods to address the bias. Six studies inadequately reported to enable the assessment of synchronization. Fifty-two (68\%) studies had low risk of bias

Table 4 presents the main features of 19 studies without synchronization of eligibility, treatment assignment, and follow-up.

\section{Discussion}

Our review showed that $20 \%(n=14 / 77)$ of the articles did not adequately report essential information of the study design. A third of reviewed articles had unclear risk of bias or high risk of selection bias and/or immortal time bias due to the choice of the time of eligibility, treatment assignment, and the start of follow-up that failed to mimic the randomization. In only $25 \%$ of the articles at risk of bias, a solution was described; however, these solutions were not adequate to eliminate the risk of bias completely. The lack of synchronization arises when investigators want to select individuals who might have better treatment adherence, i.e., select only individuals who adhered to the treatment for a given period (Table 5 (c)), or only individuals who have adhered to the treatment for a given period are classified as exposed (Table 5 (d)). To address the selection bias caused by using a post-treatment event to include individuals or predict treatment strategies in the future, Hernan et al. proposed creating a clone, i.e., an exact copy of the population, assign them to one of the treatment groups and censor when they deviate from the assigned treatment [12].

Another common reason for the lack of synchronization in observational studies using routinely collected data is due to having a grace period, i.e., individuals start to use treatment within a given period after the start of followup and eligibility (Table 5 (d)); thus, investigators can increase the number of eligible individuals. For example, to compare the effectiveness of hydroxychloroquine versus 


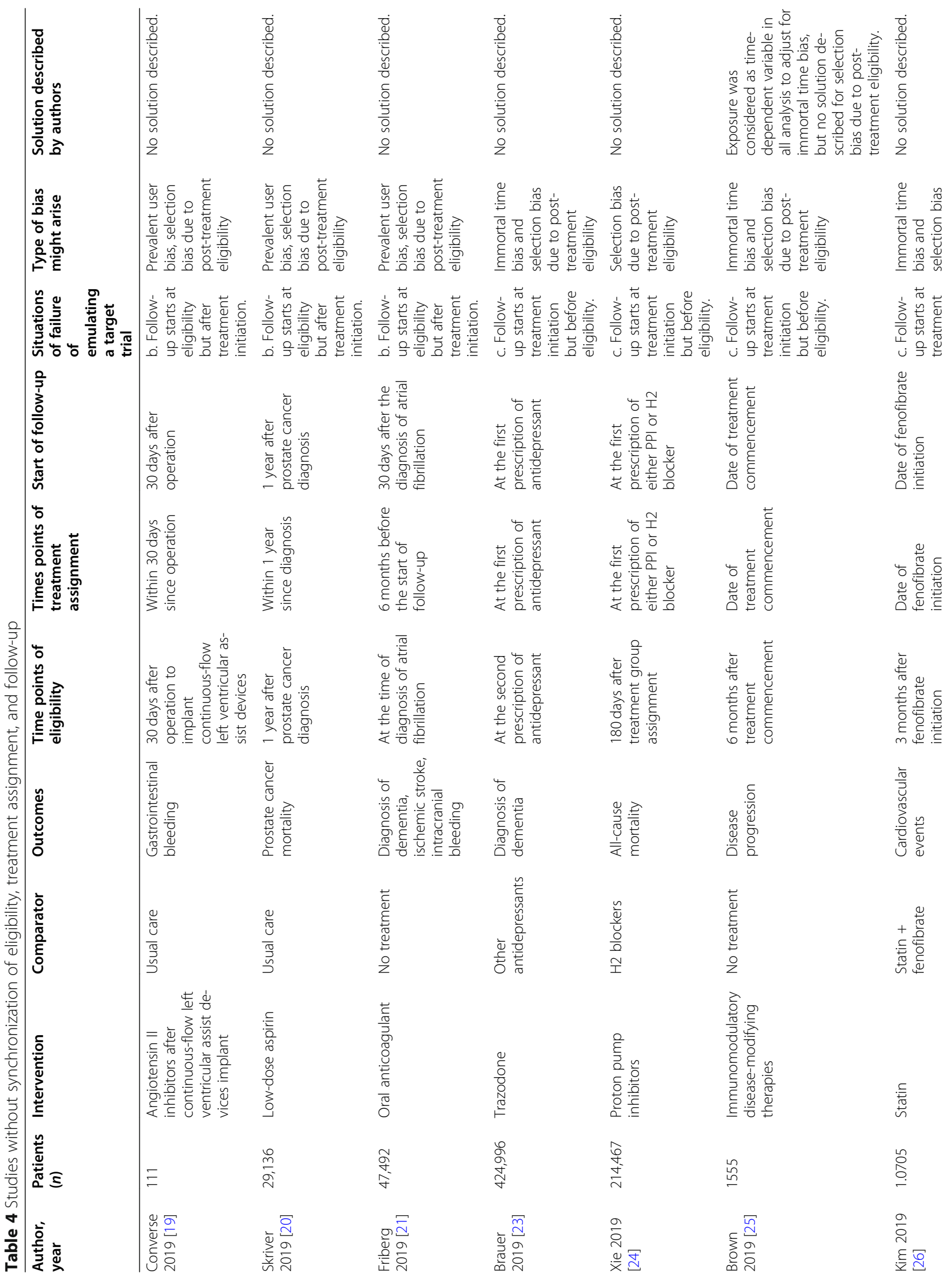




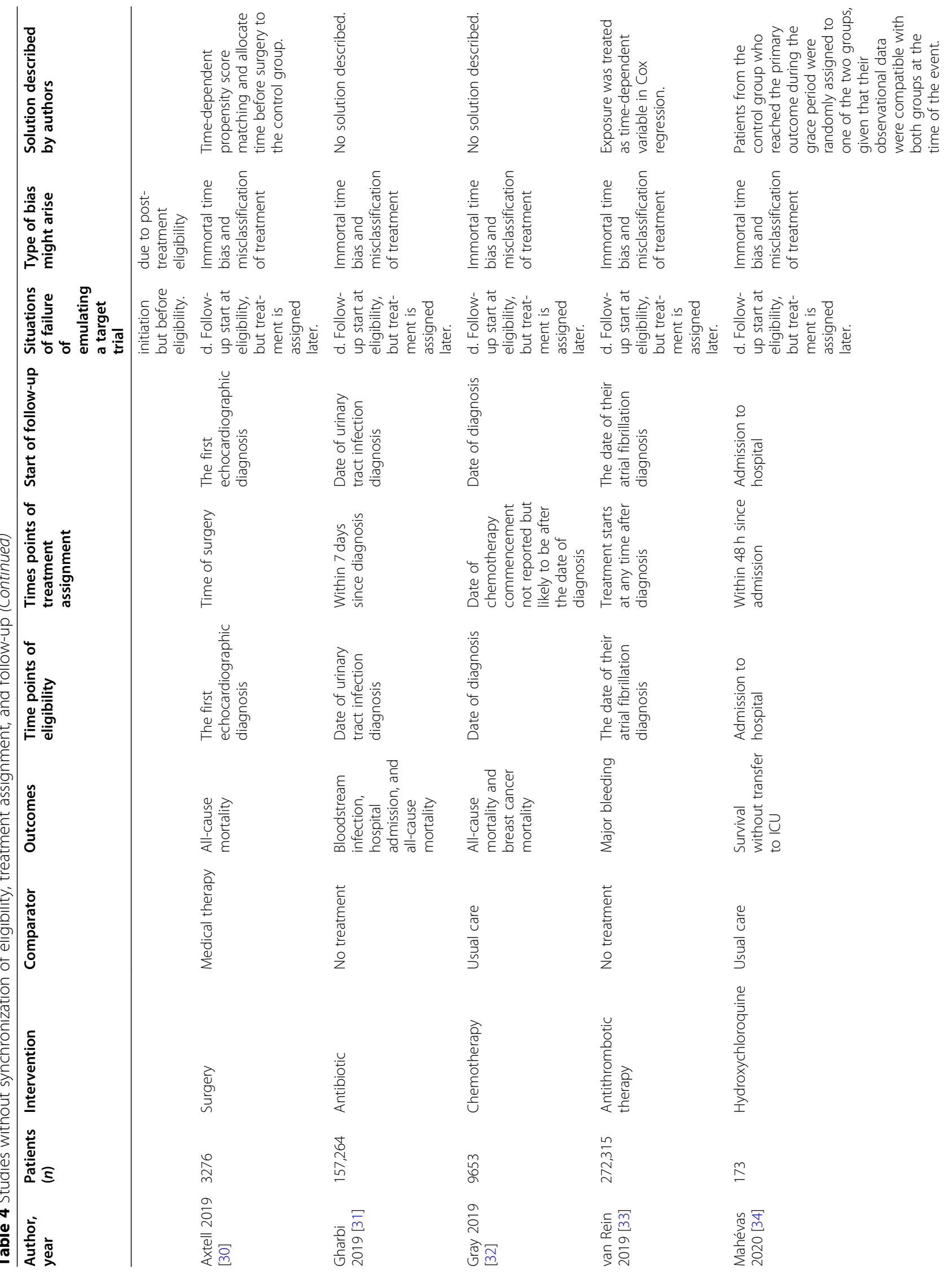




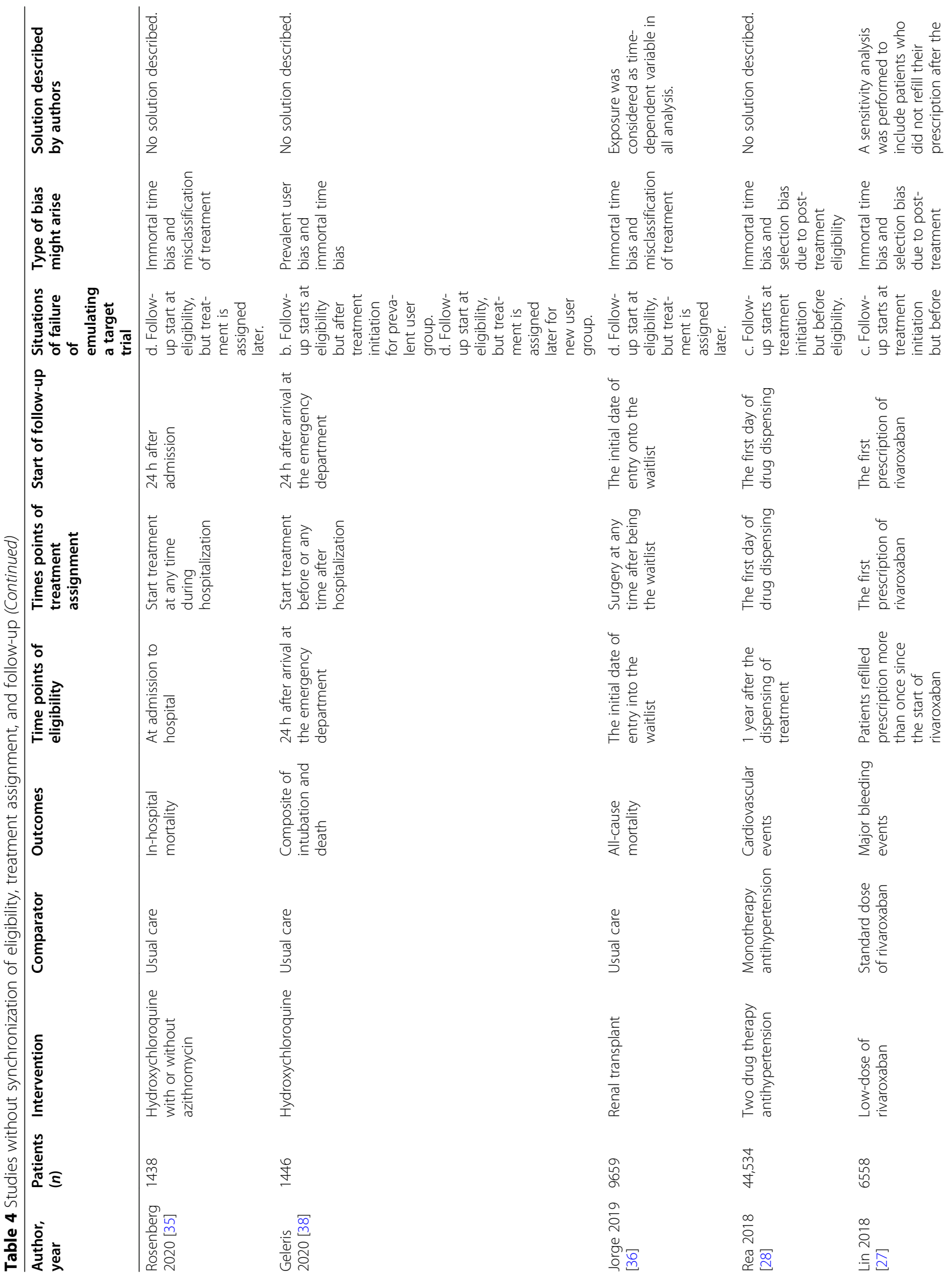




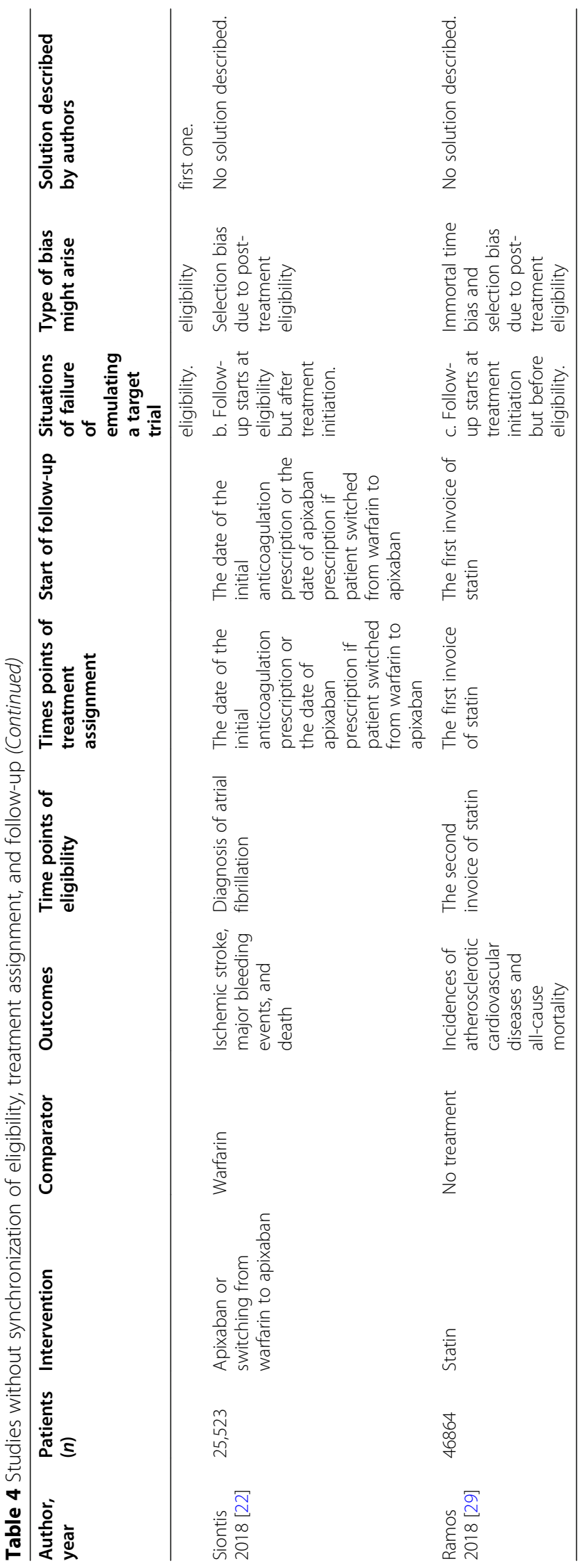


Table 5 Solutions proposed by Hernan et al. to address the risk of bias when time points of eligibility, treatment assignment, and the start of follow-up are not aligned

\begin{tabular}{|c|c|}
\hline Situations & Possible solutions \\
\hline $\begin{array}{l}\text { a. Follow-up starts after eligibility criteria completion and treatment assign- } \\
\text { ment which leads to prevalent user bias. } \\
\text { Treatment } \\
\text { assignment }\end{array}$ & Select new users [12]. \\
\hline $\begin{array}{l}\text { b. Follow-up starts at eligibility but after treatment assignment which leads } \\
\text { to prevalent user bias and selection bias due to post-treatment eligibility. } \\
\text { Treatment } \\
\text { assignment }\end{array}$ & $\begin{array}{l}\text { Select new users and ensure that individuals are not selected by an event } \\
\text { that happens after the follow-up starts [12]. }\end{array}$ \\
\hline $\begin{array}{l}\text { c. Follow-up starts before treatment assignment and eligibility which leads } \\
\text { to immortal time bias and selection bias due to post-treatment eligibility. } \\
\text { Treatment }\end{array}$ & $\begin{array}{l}\text { Keep all individuals who start the treatment since the start of follow-up, } \\
\text { create an exact copy of the population, assign them to one of the interven- } \\
\text { tion groups from the start of the follow-up, and censor when they start to } \\
\text { deviate from assigned treatment [39]. } \\
\text { One strategy which is often used to account for immortal time bias in } \\
\text { literature is to consider exposure as a time-dependent variable. However, } \\
\text { this strategy is not adequate to address the risk of selection bias due to } \\
\text { post-treatment eligibility, as an uncensored group might not be exchange- } \\
\text { able with the censored group [3]. }\end{array}$ \\
\hline $\begin{array}{l}\text { d. Follow-up starts at eligibility, but treatment is assigned later which leads } \\
\text { to immortal time bias and misclassification of treatment. } \\
\text { Treatment } \\
\text { Eligibility assignment }\end{array}$ & $\begin{array}{l}\text { 1) Randomly assign individuals to one of the treatment strategies [12]. } \\
\text { 2) Create an exact copy of the population, assign them to one of the } \\
\text { intervention groups from the start of the follow-up, and censor when they } \\
\text { start to deviate from assigned treatment [39]. } \\
\text { One strategy which is often used to account for immortal time bias is to } \\
\text { consider exposure as a time-dependent variable. However, this strategy is } \\
\text { inadequate to address the risk of misclassification, because if individuals } \\
\text { have outcomes during the grace period, we are uncertain which interven- } \\
\text { tion group they should be classified into. }\end{array}$ \\
\hline
\end{tabular}

Table 6 Checklist to determine the potential risk of bias in observational studies

\section{Guiding question}

1. When does the follow-up start?

2. When do individuals complete eligibility?

2.a. Can individuals be eligible at multiple times?

2.b. Is there any post-baseline event (i.e., an event after the follow-up starts) in the eligibility criteria?

3. When are individuals assigned to an exposed or nonexposed group?

3a. Do individuals have to use treatment for a given period to be classified as an exposed group?

3.b. Is there a grace period?

\section{Explanation}

- Check if the authors report the start of follow-up. It might be called the baseline, index date, and time zero.

- Check if authors report when individuals should complete eligibility.

- Check if individuals could be eligible at multiple times and whether authors used a strategy to overcome this: (1) choose a single eligible time and (2) choose all eligible times and conduct a sequence of trials at each eligible time.

- Check if any events after the start of follow-up are listed in the eligibility criteria, e.g. complete 2 consecutive prescriptions or no outcome for the first 2 months after the start of follow-up.

- Check if the authors report clearly when individuals are classified as exposed or nonexposed group.

- Check if individuals have to use treatment for a given period, e.g., complete 2 consecutive prescriptions to be classified as exposed and non-exposed, if not, start the treatment or complete only 1 prescription.

- Check if individuals can start the treatment sometime after the start of follow-up and eligibility. 
standard of care in the treatment for COVID-19 patients, the number of patients who initiated hydroxychloroquine immediately after hospital admission would be quite low. To increase the number of eligible patients for the analysis, investigators allowed for a grace period to assign patients who started hydroxychloroquine within $48 \mathrm{~h}$ since admission to the intervention group [34, 35]. However, a challenge of having a grace period is that we could not assign patients to one of the intervention groups at the start of the follow-up as in an RCT. If a patient had an outcome within $48 \mathrm{~h}$ since admission, it is uncertain if they should be classified as exposed or control group. To overcome the challenge of having a grace period, Hernan et al. also recommended following the strategy as above, i.e., to create an exact copy of the population, assign them to one of the intervention group, censor when they start to deviate from assigned treatment, and use inverse probability weighting to adjust for post-treatment censoring bias [12, 39] (Table 5). However, the use of such an approach was never reported in our sample. Although Hernan et al. proposed this approach in 2016, there are only a few studies applying this approach due to methodological and logistical challenges. Maringe et al. provided a detailed tutorial to perform the cloning strategy [40].

Additionally, the emulated trial framework highlights the importance of the new-user design by identifying all eligible in the defined population who started the study treatments to avoid these biases. The selection of only new users, however, might reduce the sample size and the study power [41, 42]. To address this challenge, sensitivity analysis could be used to assess the magnitude of potential bias related to including prevalent users $[41,42]$.

Furthermore, some other essential information was missing in the report of observational studies in our sample, particularly specifying if patients with contraindication with one of the evaluated treatments were excluded from the analysis. This issue could be problematic as we are uncertain if patients in different treatment groups were comparable. For example, in a study, patients who had contraindication with evaluated treatments were classified as the control group [43]. It means that patients in the intervention and control groups were not exchangeable, which violated a fundamental condition of causal inference.

Previous studies have also highlighted the incomplete reporting and potential bias in the implementation of observational studies. Luijken et al. found that $6 \%$ of the evaluated observational studies did not specify if new users or prevalent users were included, and in only half of the studies using new user design, time point of eligibility, treatment initiation, and start of follow-up were synchronized [44]. Due to these avoidable methodological pitfalls, the results of observational studies could be biased and mislead healthcare decisions [45]. The emulated trial framework which relies on synchronization of eligibility, treatment assignment, and the start of follow-up to mimic the randomization of RCT can help in reducing the risk of bias. However, the approach proposed by Hernan has also some limitations particularly in some situations, synchronization of the time points of the eligibility criteria, start of treatment, and start of follow-up is not feasible. By explicitly reporting these components and the decision made when emulating the target trials, researchers could help readers in assessing the extent that results might be influenced by bias and whether the choice of methodology to address this bias was appropriate to ensure the validity of results. We propose a checklist following the framework of emulated trials to help readers and reviewers to identify the common pitfalls of observational studies (Table 6).

Our study has some limitations. First, to ensure the feasibility of the study, we restricted the search to high impact factor journals, which might underestimate the prevalence of bias due to the lack of synchronization of eligibility, treatment assignment, and start of follow-up. However, our aim is to raise awareness of the common problems of reporting and conducting observational studies using RCD that need to be addressed in future research. Second, we were unable to determine the magnitude of the bias. For example, if there are more individuals who have outcomes during the grace period, the effect estimates would be at higher risk of bias, because these individuals are more likely to be classified in the control group. Third, we did not evaluate the risk of confounding in the included studies. Nevertheless, the emulated trial framework and the cloning strategy can address the confounding bias.

\section{Conclusions}

In conclusion, reporting of essential information of the study design in observational studies remained suboptimal. The lack of synchronization of eligibility, treatment assignment, and the start of follow-up is common among observational studies, which leads to different types of bias such as prevalent user bias, immortal time bias, and selection bias due to post-treatment eligibility. Researchers and physicians should critically appraise the results of observational studies using routinely collected data.

\section{Abbreviations}

PRISMA: Preferred reporting items for systematic reviews and meta-analyses; RCD: Routinely collected data; RCTs: Randomized controlled trials; RECORDPE: Reporting Guideline for observational studies using routinely collected data for pharmacoepidemiology

\section{Supplementary Information}

The online version contains supplementary material available at https://doi. org/10.1186/s12916-021-02151-w.

Additional file 1: Table S1. Search strategy. Table S2. Eligibility criteria. Table S3. Data extraction form. Table S4. Data Extraction Form Explanation. 


\section{Authors' contributions}

Study conception: VTN, IB, PR, RP, and ME. Data collection: VTN, ME, and MD Data analysis and interpretation: VTN, IB, RP, PR, ME, and MD. Writing: VTN, IB, $R P$, and PR. All authors read and approved the final version of the manuscript.

\section{Funding}

There is no specific funding for this project.

\section{Availability of data and materials}

The dataset is available at https://doi.org/10.5281/zenodo.5543469.

\section{Declarations}

\section{Ethics approval and consent to participate}

No ethical approval was required as the study did not use personal data.

\section{Consent for publication}

Not applicable

\section{Competing interests}

The authors declare that they have no competing interests.

\section{Author details}

Centre of Research Epidemiology and Statistics (CRESS), Inserm, Université de Paris, F-75004 Paris, France. ${ }^{2}$ Meta-Research Innovation Centre at Stanford (METRICS), Stanford University, 1265 Welch Rd, Stanford, CA 94305, USA. ${ }^{3}$ Cochrane France, AP-HP, 75004 Paris, France. ${ }^{4}$ Centre d'Epidémiologie Clinique, Hôpital Hôtel Dieu, Assistance Publique des Hôpitaux de Paris (APHP), F-75004 Paris, France.

Received: 24 June 2021 Accepted: 4 October 2021

Published online: 23 November 2021

\section{References}

1. Stuart EA, Ackerman B, Westreich D. Generalizability of randomized trial results to target populations: design and analysis possibilities. Res Soc Work Pract. 2017;28(5):532-7. https://doi.org/10.1177/1049731517720730.

2. McDonald AM, Knight RC, Campbell MK, Entwistle VA, Grant AM, Cook JA, et al. What influences recruitment to randomized controlled trials? A review of trials funded by two UK funding agencies. Trials. 2006;7(1):9. https://doi. org/10.1186/1745-6215-7-9.

3. Hernan M, Robins JM. Causal inference: what if. Boca Raton: Chapman \& Hall/CRC; 2020

4. Hernán MA, Robins JM. Using big data to emulate a target trial when a randomized trial is not available. Am J Epidemiol. 2016;183(8):758-64. https://doi.org/10.1093/aje/kwv254.

5. Gershman B, Guo DP, Dahabreh IJ. Using observational data for personalized medicine when clinical trial evidence is limited. Fertil Steril. 2018;109(6):946-51. https://doi.org/10.1016/j.fertnstert.2018.04.005.

6. Hemkens LG, Contopoulos-loannidis DG, loannidis JPA. Routinely collected data and comparative effectiveness evidence: promises and limitations. Can Med Assoc J. 2016;188(8):E158-64. https://doi.org/10.1503/cmaj.150653.

7. Dreyer NA. Making observational studies count: shaping the future of comparative effectiveness research. Epidemiology. 2011;22(3):295-7.

8. Concato J, Lawler EV, Lew RA, Gaziano JM, Aslan M, Huang GD. Observational methods in comparative effectiveness research. Am J Med. 2010;123(12):e16-23. https://doi.org/10.1016/j.amjmed.2010.10.004.

9. D'Agostino RB. Estimating treatment effects using observational data. JAMA. 2007;297(3):314-6. https://doi.org/10.1001/jama.297.3.314.

10. Lévesque LE, Hanley JA, Kezouh A, Suissa S. Problem of immortal time bias in cohort studies: example using statins for preventing progression of diabetes. BMJ. 2010;340(mar12 1):b5087. https://doi.org/10.1136/bmj.b5087.

11. ludici M, Porcher R, Riveros C, Ravaud P. Time-dependent biases in observational studies of comparative effectiveness research in rheumatology. A methodological review. Ann Rheum Dis. 2019;78(4):562-9. https://doi.org/10.1136/annrheumdis-2018-214544.

12. Hernán MA, Sauer BC, Hernández-Díaz S, Platt R, Shrier I. Specifying a target trial prevents immortal time bias and other self-inflicted injuries in observational analyses. J Clin Epidemiol. 2016;79:70-5. https://doi.org/10.101 6/j.jclinepi.2016.04.014.
13. García-Albéniz X, Hsu J, Hernán MA. The value of explicitly emulating a target trial when using real world evidence: an application to colorectal cancer screening. Eur J Epidemiol. 2017;32(6):495-500. https://doi.org/10.1 007/s10654-017-0287-2.

14. Sterne JAC, Hernán MA, Reeves BC, Savović J, Berkman ND, Viswanathan M, et al. ROBINS-I: a tool for assessing risk of bias in non-randomized studies of interventions. BMJ. 2016;355:i4919. https://doi.org/10.1136/bmj.i4919.

15. Liberati A, Altman DG, Tetzlaff J, Mulrow C, Gøtzsche PC, loannidis JPA, et al. The PRISMA statement for reporting systematic reviews and meta-analyses of studies that evaluate healthcare interventions: explanation and elaboration. BMJ. 2009;339(jul21 1):b2700. https://doi.org/10.1136/bmj.b2700.

16. Ouzzani M, Hammady H, Fedorowicz Z, Elmagarmid A. Rayyan—a web and mobile app for systematic reviews. Syst Rev. 2016;5(1):210. https://doi.org/1 0.1186/s13643-016-0384-4

17. Langan SM, Schmidt SAJ, Wing K, Ehrenstein V, Nicholls SG, Filion KB, et al. The reporting of studies conducted using observational routinely collected health data statement for pharmacoepidemiology (RECORD-PE). BMJ. 2018; 363:k3532. https://doi.org/10.1136/bmj.k3532.

18. McHugh ML. Interrater reliability: the kappa statistic. Biochem Med (Zagreb). 2012;22(3):276-82. https://doi.org/10.11613/BM.2012.031.

19. Converse MP, Sobhanian M, Taber DJ, Houston BA, Meadows HB, Uber WE. Effect of angiotensin II inhibitors on gastrointestinal bleeding in patients with left ventricular assist devices. J the Am Coll Cardiol. 2019;73(14):176978. https://doi.org/10.1016/j.jacc.2019.01.051.

20. Skriver C, Dehlendorff C, Borre M, Brasso K, Larsen SB, Dalton SO, et al. Use of low-dose aspirin and mortality after prostate cancer diagnosis: a nationwide cohort study. Ann Intern Med. 2019;170(7):443-52. https://doi. org/10.7326/M17-3085

21. Friberg L, Andersson T, Rosenqvist M. Less dementia and stroke in low-risk patients with atrial fibrillation taking oral anticoagulation. Eur Heart J. 2019; 40(28):2327-35. https://doi.org/10.1093/eurheartj/ehz304.

22. Siontis KC, Zhang $X$, Eckard A, Bhave N, Schaubel DE, He K, et al. Outcomes associated with apixaban use in patients with end-stage kidney disease and atrial fibrillation in the United States. Circulation. 2018;138(15):1519-29. https://doi.org/10.1161/CIRCULATIONAHA.118.035418.

23. Brauer R, Lau WCY, Hayes JF, Man KKC, Osborn DPJ, Howard R, et al. Trazodone use and risk of dementia: a population-based cohort study. PLOS Medicine. 2019;16(2):e1002728. https://doi.org/10.1371/journal.pmed.100272 8.

24. Xie Y, Bowe B, Yan Y, Xian H, Li T, Al-Aly Z. Estimates of all cause mortality and cause specific mortality associated with proton pump inhibitors among US veterans: cohort study. BMJ. 2019;365:11580. https://doi.org/10.1136/bmj. 11580

25. Brown JWL, Coles A, Horakova D, Havrdova E, Izquierdo G, Prat A, et al. Association of initial disease-modifying therapy with later conversion to secondary progressive multiple sclerosis. JAMA. 2019;321(2):175-87. https:// doi.org/10.1001/jama.2018.20588.

26. Kim NH, Han KH, Choi J, Lee J, Kim SG. Use of fenofibrate on cardiovascular outcomes in statin users with metabolic syndrome: propensity matched cohort study. BMJ. 2019;366:15125. https://doi.org/10.1136/bmj.I5125.

27. Lin $Y-C$, Chien S-C, Hsieh Y-C, Shih C-M, Lin F-Y, Tsao N-W, et al. Effectiveness and safety of standard- and low-dose rivaroxaban in Asians with atrial fibrillation. J Am Coll Cardiol. 2018;72(5):477-85. https://doi.org/1 0.1016/j.jacc.2018.04.084

28. Rea F, Corrao G, Merlino L, Mancia G. Early cardiovascular protection by initial two-drug fixed-dose combination treatment vs. monotherapy in hypertension. Eur Heart J. 2018;39(40):3654-61. https://doi.org/10.1093/ eurheartj/ehy420.

29. Ramos R, Comas-Cufí M, Martí-Lluch R, Balló E, Ponjoan A, Alves-Cabratosa L, et al. Statins for primary prevention of cardiovascular events and mortality in old and very old adults with and without type 2 diabetes: retrospective cohort study. BMJ. 2018;362:k3359. https://doi.org/10.1136/bmj.k3359.

30. Axtell AL, Bhambhani V, Moonsamy P, Healy EW, Picard MH, Sundt TM, et al. Surgery does not improve survival in patients with isolated severe tricuspid regurgitation. J Am Coll Cardiol. 2019;74(6):715-25. https://doi.org/10.1016/j. jacc.2019.04.028.

31. Gharbi M, Drysdale JH, Lishman H, Goudie R, Molokhia M, Johnson AP, et al. Antibiotic management of urinary tract infection in elderly patients in primary care and its association with bloodstream infections and all cause mortality: population based cohort study. BMJ. 2019;364:1525. https://doi. org/10.1136/bmj.I525. 
32. Gray E, Marti J, Wyatt JC, Brewster DH, Hall PS, Group Sa. Chemotherapy effectiveness in trial-underrepresented groups with early breast cancer: a retrospective cohort study. Plos Medicine. 2020;16(12):e1003006.

33. van Rein N, Heide-Jørgensen U, Lijfering Willem M, Dekkers Olaf M, Sørensen Henrik T, Cannegieter SC. Major bleeding rates in atrial fibrillation patients on single, dual, or triple antithrombotic therapy. Circulation. 2019; 139(6):775-86. https://doi.org/10.1161/CIRCULATIONAHA.118.036248.

34. Mahévas M, Tran V-T, Roumier M, Chabrol A, Paule R, Guillaud C, et al. Clinical efficacy of hydroxychloroquine in patients with COVID-19 pneumonia who require oxygen: observational comparative study using routine care data. BMJ. 2020;369:m1844.

35. Rosenberg ES, Dufort EM, Udo T, Wilberschied LA, Kumar J, Tesoriero J, et al. Association of treatment with hydroxychloroquine or azithromycin with inhospital mortality in patients with COVID-19 in New York State. JAMA. 2020; 323(24):2493-502. https://doi.org/10.1001/jama.2020.8630.

36. Jorge A, Wallace ZS, Lu N, Zhang Y, Choi HK. Renal transplantation and survival among patients with lupus nephritis: a cohort study. Ann Intern Med. 2019;170(4):240-7. https://doi.org/10.7326/M18-1570.

37. Larochelle MR, Bernson D, Land T, Stopka TJ, Wang N, Xuan Z, et al. Medication for opioid use disorder after nonfatal opioid overdose and association with mortality. Ann Intern Med. 2018;169(3):137-45. https://doi. org/10.7326/M17-3107.

38. Geleris J, Sun Y, Platt J, Zucker J, Baldwin M, Hripcsak G, et al. Observational study of hydroxychloroquine in hospitalized patients with COVID-19. N Engl J Med. 2020;382(25):2411-8. https://doi.org/10.1056/NEJMoa2012410.

39. Hernán MA. How to estimate the effect of treatment duration on survival outcomes using observational data. BMJ. 2018;360:k182. https://doi.org/1 $0.1136 / \mathrm{bmj} . \mathrm{k} 182$

40. Maringe C, Benitez Majano S, Exarchakou A, Smith M, Rachet B, Belot A, et al. Reflection on modern methods: trial emulation in the presence of immortal-time bias. Assessing the benefit of major surgery for elderly lung cancer patients using observational data. Int J Epidemiol. 2020;49(5):171929. https://doi.org/10.1093/ije/dyaa057.

41. Ray WA. Evaluating medication effects outside of clinical trials: new-user designs. Am J Epidemiol. 2003;158(9):915-20. https:/doi.org/10.1093/aje/ kwg231.

42. Yoshida K, Solomon DH, Kim SC. Active-comparator design and new-user design in observational studies. Nat Rev Rheumatol. 2015;11(7):437-41. https://doi.org/10.1038/nrrheum.2015.30.

43. Lagier J-C, Million M, Gautret P, Colson P, Cortaredona S, Giraud-Gatineau A, et al. Outcomes of 3,737 COVID-19 patients treated with

hydroxychloroquine/azithromycin and other regimens in Marseille, France: a retrospective analysis. Travel Med Infect Dis. 2020;36:101791.

44. Luijken K, Spekreijse JJ, van Smeden M, Gardarsdottir H, Groenwold RHH. New-user and prevalent-user designs and the definition of study time origin in pharmacoepidemiology: a review of reporting practices. Pharmacoepidemiol Drug Saf. 2021;30(7):960-74. https://doi.org/10.1002/ pds.5258.

45. Gueyffier F, Cucherat M. The limitations of observation studies for decision making regarding drugs efficacy and safety. Therapies. 2019;74(2):181-5. https://doi.org/10.1016/j.therap.2018.11.001.

\section{Publisher's Note}

Springer Nature remains neutral with regard to jurisdictional claims in published maps and institutional affiliations.

Ready to submit your research? Choose BMC and benefit from:

- fast, convenient online submission

- thorough peer review by experienced researchers in your field

- rapid publication on acceptance

- support for research data, including large and complex data types

- gold Open Access which fosters wider collaboration and increased citations

- maximum visibility for your research: over $100 \mathrm{M}$ website views per year

At BMC, research is always in progress.

Learn more biomedcentral.com/submissions 